\title{
Accediendo a la tenencia de la tierra: integración política de los libres de San Antonio de Quilichao en la jurisdicción de Caloto, provincia de Popayán (1740-1808)
}

Richard Bolaños

Recibido: Agosto de 2015

Aprobado: Enero de 2016

\section{Resumen}

En el presente artículo pretendemos estudiar cómo los libres de San Antonio de Quilichao al asentarse accedieron a la tenencia de tierra, dándole variados usos y logrando vincular su producción no solo al mercado local sino a la provincia de Popayán. Para alcanzar lo anterior, los libres contaron con la favorabilidad de condiciones tales como la producción agrícola, la cría de ganados, el desarrollo de pulperías, la especialización en distintos oficios y la utilización de una red de distribución comercial.

Palabras Claves: Reformas Borbónicas, Economías campesinas, acceso a la tierra, uso de la tierra, vecinos, libres, Provincia de Popayán.

\section{Abstract}

The current article intend to study how the settlement of free people from San Antonio de Quilichao get to access the land ownership attributing to its various usages and linking the production to the local market through much of the province of Popayan. We support the idea that for achieving this purpose, a number of favorable conditions was

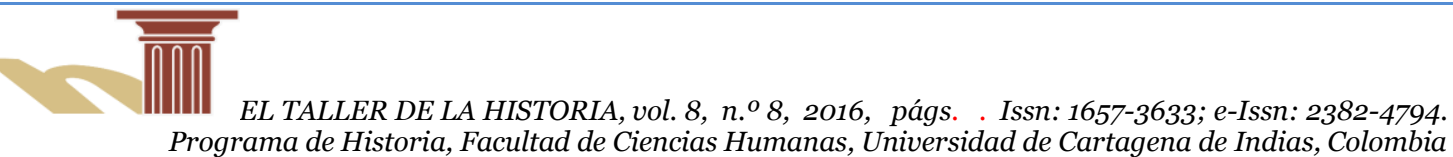


stated such as: agricultural production, cattle breeding, the development of stores, specializing in different occupations and the use of a commercial distribution network.

Key words: Political Integration, Bourbon reforms, neighborhood, allegiance, village, free people, Province of Popayan.

\section{Introducción}

Un aspecto importante y poco trabajado en la gobernación de Popayán ${ }^{1}$ es el efecto del reformismo borbónico en las campañas de poblamiento emprendidas por la corona en el Virreinato de la Nueva Granada y la posibilidad de integrar políticamente a los pobladores libres². Para contextualizar la temática, es necesario tener en cuenta la llegada a la ciudad de Cartagena del Virrey Sebastián Eslava en 1740, hecho que repercutió significativamente en la manera en que se ejercía la política y el mercado; específicamente, la transformación de las instituciones castellanas en los cabildos locales y el reconocimiento del "estado llano", acciones que introdujeron cambios que afectaron en la parte baja de la esfera social3.

En esa parte baja se encontraba la población considerada libre que estaba presente desde antes de la implantación de las reformas como producto del mestizaje. Su crecimiento se debió al poblamiento paulatino de zonas que no estaban bajo los ordenamientos de la Corona ubicadas en lugares rurales apartados, las vedas de los caminos, caños, ríos y ciénagas que se desarrollaron durante la segunda mitad del siglo XVIII. Si lograron prosperar en estos espacios, se debió a la explotación de los recursos naturales, un acceso a la tierra que les permitió desarrollar una agricultura a pequeña escala, el desarrollo de actividades mineras, artesanales y comerciales 4.

\footnotetext{
${ }^{1}$ La Provincia de Popayán fue fundada durante la segunda mitad del siglo XVI, también se le conoce como Gobernación de Popayán, siendo correcto el uso de ambos nombres.
}

2 Richard A. Bolaños Rodas. "El Impacto del Reformismo Borbónico en la Nueva Granada. El caso de los indios de Jámbalo y el asiento de libres de San Antonio de Quilichao en la Jurisdicción de Caloto, Provincia de Popayán 1750- 1810”. (Tesis de Pregrado, Cali: Universidad del Valle, 2013).

3 David Brading. "La España de los Borbones y su imperio americano", en América Latina en la época colonial, comp. Miguel León Portilla, (Madrid: Crítica, 1990), 85-126; Margarita Garrido. Reclamos y representaciones. Variaciones sobre la política en el nuevo Reino de Granada, 1770-1815, (Bogotá: Banco de la República, 1993); Anthony Mc Farlane. "Renovación: el establecimiento del Virreinato" en Colombia antes de la Independencia, (Bogotá: Banco de la República, 1997).

4 Adolfo Meisel Roca. "Esclavitud, mestizaje y haciendas en la provincia de Cartagena. 1533-1851", en El Caribe colombiano. Selección de textos históricos, ed. Gustavo Bell Lemus (Barranquilla: Universidad 
$\mathrm{Al}$ respecto, un punto importante y a tener en cuenta, que el proyecto reformista tenía entre sus objetivos sacar de la barbarie política complejas y variopintas poblaciones producto del mestizaje, a través de las ya conocidas campañas de poblamiento, consistentes en fundar poblaciones que permitieran trasladar e integrar políticamente a la gente libre que vagaba y vivía en los montes y zonas abnegadas. Con ello, se buscó conservar el orden moral y público, pero también crear una oferta de mano de obra para las haciendas y minas, así como agrupar a la población con el fin de asumir derechos y deberes como comunidad5.

Esa política, convirtió a la población libre en un grupo social que empezó a "surgir" bajo rasgos peculiares al aliento de las reformas, como lo fue su integración política al orden colonial. Con dicha integración, habrá que preguntarse ¿Por qué interesarse la Corona en integrar políticamente a un sector específico de la población colonial, hasta ese momento sin derechos ni reconocimientos y sin deberes? Adicionalmente, ¿̇Por qué en algunos casos la Corona estableció pactos de negociación con los conocidos en la época como el "vajo pueblo"? Y finalmente, ¿Cuál fue el momento en que se trazó la posibilidad para acceder a la vecindad y al vasallaje que bien eran las herramientas claves para acceder a la tenencia de la tierra, y el mercado?

Frente al primer interrogante podríamos decir que los intereses son diversos. Uno de ellos radica en evitar sublevaciones en pueblos de indios y de libres. Por otro lado, la importancia de proveer la defensa de los caminos y de las ciudades de los indios infieles, hacía importante la integración de sectores de libres los cuáles ante la existencia de recursos y ante la necesidad de producir bienes alimenticios y materiales tanto para las áreas rurales como para las ciudades, que en suma eran productos básicos de primera

del Norte, 1988); Margarita Garrido. Libres de todos los colores en la sociedad colonial tardía: discursos y prácticas, (Cali: Universidad del Valle, 1998); Marta Herrera. "Libres de todos los colores": el ordenamiento social en las llanuras del Caribe, siglo XVIII", en El Caribe colombiano en la nación colombiana, Memorias X Cátedra Anual de Historia "Ernesto Restrepo Tirado", ed. Alberto Abello (Bogotá: Museo Nacional de Colombia/Observatorio del Caribe Colombiano, 2006); Hugues Sánchez, "De esclavos a campesinos, de la "roza" al mercado: tierra y producción de los "libres de todos los colores" en la gobernación de Santa Marta (1740-1810)", en Historia Crítica, No. 43, Enero-Abril, (Bogotá: Uniandes, 2011), 130155 .

5 Hugues Sánchez. "Amancebamiento, poligamia, lujuria y otros excesos de la población libre en el Caribe Colombiano. El nacimiento de una Cultura. 1750-1880", en eds. Hugues Sánchez y Leovedis Martínez. Historia, Identidades, Cultura Popular y Música Tradicional en el Caribe Colombiano. (Valledupar: Ediciones Unicesar, 2004), 45-60. 
necesidad, integrados como mano de obra. También, las autoridades intentaron integrar zonas de frontera que se habían conservado sin "ley ni orden". Todos estos intereses fuero los propósitos que buscaban alcanzarse con las campañas de poblamiento del siglo XVIII, intentando así establecer en vecindad a la población en condición de libres ${ }^{6}$.

Es dentro de este contexto que es importante reconocer, que los pactos de negociación que establecía la corona con los sectores del "vajo pueblo" han sido invisibilizados. Por un lado, podríamos decir que un sector importante de la historiografía dedicada al tema que se ha concentrado en mirar las acciones punitivas desarrolladas por la Corona dentro de estas campañas de poblamiento, las cuales no debemos desconocer porque existieron actos que han sido observados bajo las riendas coercitivas de un Estado moderno, tal como lo ha planteado y propuesto Foucault7 Sin embargo, no podemos considerar las acciones punitivas como los únicos actos existentes, siendo importante entonces ubicar aquellos espacios sociales donde hubo pactos de negociación y voluntad entre ambas partes que permitieron acceder en algunos casos a privilegios en derecho a la población libre. Una discusión insistente de la historiografía ha sido la de expresar la ausencia de reglas en sociedades que se encontraban en condición de libres al no existir un control social organizado desde las instituciones. Ahora bien, aquellas visiones han cambiado a partir de planteamientos de historiadores que han encontrado fundamentos en el derecho, para considerar que dichas reglas siempre existieron ${ }^{8}$.

Uno de estos planteamientos proviene de la historiadora Tamar Herzog, quien estudiando la autonomía de algunas sociedades hispanoamericanas en la adjudicación de apellidos en condición de libres, consideró que gran parte de la historiografía ha pecado analíticamente al igualar la falta de mecanismos de coerción con una libertad, y la libertad con falta de reglas. Idea errónea de base que aceptaba el hecho que, si las personas podían actuar libremente sin padecer consecuencias, era por qué sus actuaciones eran

\footnotetext{
${ }^{6}$ Hugues Sánchez, "De esclavos a campesinos...”; Marta Herrera. Popayán, la unidad de lo diverso: territorio, población y poblamiento en la Provincia de Popayán, siglo XVIII. (Bogotá: Uniandes, 2009); Hugues Sánchez, "Tenencia de la tierra, mano de obra, mercados y productividad en la frontera: españoles, indígenas y comunidades campesinas en la gobernación de Santa Marta, 1700-1810”. Tesis de Doctorado (Sevilla: Universidad Pablo de Olavide, 2010).

7 Marta Herrera. Popayán, la unidad de lo diverso...; Marta Herrera. Ordenar para controlar. Ordenamiento espacial y control político en las Llanuras del caribe y en los Andes Centrales Neogranadinos. Siglo XVIII. (Bogotá: Instituto Colombiano de Antropología e Historia- Academia Colombiana de Historia, 2002); Hugues Sánchez. "Amancebamiento, poligamia, lujuria...”.

8 Tamar Herzog. Vecinos y Extranjeros. Hacerse español en la edad moderna. (Madrid: Alianza, 2006).
} 
legítimas y permitidas, contraargumentando que existían individuos que protegían sus intereses a veces al abrigo de las instituciones y otras veces independientemente de ellas; siendo las reglas invocadas a favor de estos intereses y en virtud de los mismos que las reglas se imponían. Por tal motivo a falta de un interés particular y a falta de una persona a la cual proteger, imperaba la libertad 9 .

La segunda cuestión a entender dentro de los pactos de negociación es el carácter del Estado borbónico tal como lo plantea Paul Monod, quién pone en consideración dos aspectos intrínsecos dentro de ese sentido integrador cuyos postulados permitieron acercarnos a perspectivas de análisis no muy trabajadas al abrigo de las reformas en la provincia de Popayán como bien serían la inserción política a la vecindad y el vasallaje de descendientes de libres. Siguiendo a Paul Monod, consideramos que el reformismo borbónico fue inclusivo e integrador y puso de manifiesto cómo se afianzaría la nueva "cara benévola" del conocido Estado Ilustrado en un área específica de ésta gobernación ${ }^{10}$.

Por último, es menester analizar qué determinaría el momento en el cual se trazó un margen para que las poblaciones de libres accedieran a la vecindad -exigido a partir del entendimiento del derecho jurídico castellano-que no solo llevaría a estudiar el proceso de integración que propuso la reforma, sino también, aclarar en qué momento estuvieron por fuera de la misma. Según el derecho castellano, podría considerarse que estaba por fuera de la ley aquellos quiénes vivían sin acoger la religión católica, sin deberes de vasallaje y por ende, sin derechos. Ello significaba además que escapaban del régimen de restricción que tenía el sistema jurídico castellano para quiénes sí vivían avecindados, tal y como lo definía el diccionario de autoridades en la época, libres de "cargas" y "tributos" para con una localidad o individuos sin servidumbre alguna"1.

9 Tamar Herzog. "Nombres y apellidos: ¿cómo se llamaban las personas en Castilla e Hispanoamérica durante la época moderna?”, en Jahrbuch Für Geschichte Lateinamerikas, No. 44, (Böhlau Verlag Köln, Weimar, Wien 2007).

${ }_{10}$ Paul Monod. "Estado, nación y monarquía en el siglo XVIII: visión comparativa" en Las monarquías del Antiguo Régimen, ¿̇monarquías compuestas? (Madrid: Editorial Complutense, 1996), 11-29.

${ }^{11}$ En el Diccionario de Autoridades de 1739 se señala que vecino "se llama también el que tiene casa, y hogar en un Pueblo, y contribuye en él en las cargas, ú repartimientos, aunque actualmente no viva en él". En tanto se denomina libre a la persona "que tiene libertad, y no está sujeto a servidumbre alguna". RAE, 1739: 428. 
Según lo anterior, si existía desde el derecho jurídico castellano una diferenciación entre quienes vivieron bajo la ley -en garantía de libertades y derechos- frente a los que no ${ }^{12}$, se hace necesario identificar dos tipos de "libres". En primera instancia, tenemos el tipo de "libre errante" el cual lo definimos previamente a la implantación de las reformas en 1740, siendo todo individuo que no se encontraba asentado en algún lugar del reino; que vivía de forma libre pero errante al no contar con residencia fija; que por el hecho de no estar asentado, no se acogía a la promulgación de ordenamiento de integración de la Corona al encontrarse sin policía, feligresía, ni declaración de una patria -ésta última entendida desde lo local-; el cual subsistía del regateo o alguna otra actividad por lo general ilícita como el contrabando de licores, el abigeato o de "trato y contrato" con negros esclavos en las minas.

Lo importante fue que ya en ejecución el reformismo borbónico en el reino, el "libre errante" tuvo la posibilidad de integrarse en comunidad a través de la vecindad y posteriormente del vasallaje hacia el Rey mediante la negociación ${ }^{13}$. Es a partir de allí, que identificamos el tipo de "libre integrado". Éste se caracterizaba por usar la libertad de los individuos, libertades propias del "Estado Ilustrado", para estabilizarse en un sitio fijo mientras la Corona los aceptaba-, permitiéndoles que no vivieran en las ciudades sino en sus asentamientos o comunidades fronterizas y rurales, pero a su vez colocaba a su servicio los medios necesarios para establecer el lugar e instalar pequeñas autoridades locales como: jueces, alcaldes, protectores de naturales, facilitar la construcción de la iglesia y todo lo que estuviera a su alcance para beneficio de la comunidad y funciones de autogobierno. En contraparte no solo se debían establecer en comunidad, sino también era necesario que los libres en su nueva condición debían reconocerse a sí mismos y públicamente como "ifieles y leales vasallos, del Rey".

Comprendiendo todo lo anterior, la integración política de la población libre exige una visión que debe actualizarse a través de la identificación de los intereses que la Corona determinó para integrarlos; matizar la falta de reglas en estas poblaciones de libres

12 Annick Lempérière. Entre Dios y el Rey: la República, la cuidad de México de los siglos XVI-XIX. (México: Fondo de Cultura Económica, 2013); Tamar Herzog. Vecinos y Extranjeros...

13 Por vecino se entiende que, "era alguien que había decidido vivir en la comunidad y que estaba dispuesto a comprometerse con ella de forma duradera, beneficiándose de sus privilegios y cargando con sus obligaciones. La genealogía, el origen y la forma en que hubiera entrado en el territorio podían facilitar o dificultar la inserción, pero no la determinaban...” Tamar Herzog. Vecinos y Extranjeros, 15. 
junto a una visión del carácter negociador del Estado borbónico ilustrado, y de considerar el momento en que se dio la oportunidad para que los libres accedieran a la vecindad y el vasallaje. Esa mirada se une a la reducción del nivel de análisis a escala micro'14. Esto haría posible mostrar el surgimiento de un sitio de libres junto al desarrollo de una economía local una vez que conservaron la tenencia de la tierra y le dieron diversos usos; al igual que visibilizaría un proceso de integración de las calidades que vivían allí o se seguían agrupando; permitiría entender el proceso que afrontaron como comunidad para acceder a la vecindad; y por último, llevaría a demostrar cómo se incluyeron en el vasallaje.

\section{El surgimiento del sitio de libres de Quilichao}

Entre los años de 1750 a 1787 se desarrolló un largo y dilatado pleito entre los libres de Quilichao contra la familia Arboleda y el Cabildo de Caloto, conflicto que consta de dos procesos. El primero, implicó a los libres de Quilichao frente a la familia Arboleda por el uso de los montes denominados mochique o monchique y por los derechos de propiedad sobre las tierras que ocupaba la población de libres. El segundo proceso involucró a los libres de Quilichao contra la familia Arboleda y el Cabildo de Caloto por las minas de Quinimayó y la autonomía política del sitio de libres de Quilichao frente al Cabildo de Caloto ${ }^{15}$.

Partiendo de la documentación, primeramente debemos indicar cómo surgió el sitio de libres de Quilichao. Tenemos noticias de que el sitio se empezó a formar en 1740; según informaba Francisco Antonio Arboleda en el llano de "Quilichao" se había formado una "grande población de jente" sin "oficios públicos" ni "hacienda propia" que "vendía esclavos y recibía oro a cambio". Igualmente anotaba que si bien la población tenía "plaza, calles e iglesia" estaría fuera de "la ley y el orden religioso" 16.

De la documentación se infiere que el sitio surgió a la sombra de las minas explotadas y de las haciendas y hatos ganaderos que se fueron fundando en el llano de Quilichao a lo

14 Herrera, Martha. "Popayán: la unidad de lo diverso. Territorio, población y poblamiento en la Provincia de Popayán, siglo XVIII." (2009).

${ }_{15}$ Archivo General de la Nación, Bogotá, Colombia (en adelante AGN), Poblaciones del Cauca (en adelante PC), Rollo 4 y 5, ff. 158-724. (Pleito entre la Familia Arboleda y los libres de Quilichao por el uso de tierras y montes, la explotación de las minas de Quinimayó y la autonomía política frente a Caloto).

${ }^{16}$ AGN, PC, Rollo 4, f. 597r. 
largo del siglo XVIII. La existencia de estas condiciones representa el motivo central de su agrupamiento dada la posibilidad de comercio que ofrecía la presencia de esclavos, los cuales demandaban géneros en alimentos, ropa y servicios porque podían pagar en oro dichas necesidades. Por ello, se informaba que "de algunos años a esta parte han empezado a poblar ciertas gentes advenedizas pobres y del estado bajo, que no tienen otros bienes ni haciendas que lo que les producen los tratos que hacen con los negros y esclavos que laborean las minas de sus inmediaciones, que son de veinte a veintiuna $[\ldots]{ }^{\prime 1}$.

Respecto a su ubicación, el sitio de libres se encontraba como reposa en la documentación, distante una legua con corta diferencia de la ciudad de Caloto dentro de su jurisdicción hay un sitio "llamado de Quilichao"18, señalado con la letra (B) como se verá en el mapa No. 1 que insertamos.

Ahora es necesario identificar los elementos que hicieron posible el surgimiento del sitio de libres. La principal condición fue el comercio de oro efectuado por los esclavos que laboraban en dichas minas. Al respecto se decía: "[...] y todos aquellos habitadores es gente pobre y plebeya de diferentes parajes a excepción de uno dicho sujeto tratante que viene de afuera por la codicia del oro que rescatan de los negros con sus cortos géneros y en conocido perjuicio de los dueños de cuadrilla y que las tiendas que allí existen son como unas pulperías mestizas que tienen algunos géneros de ropas y otros comestibles $[\ldots]{ }^{\prime \prime} 19$

\footnotetext{
${ }_{17}$ AGN, PC, Rollo 5, f. 694r.

18 AGN, PC, Rollo 5, f. 694r.

${ }_{19}$ AGN, PC, Rollo 5, f. 670r.
} 
Mapa No. 1: Panorama de la Jurisdicción de Caloto (1762) ${ }^{20}$.

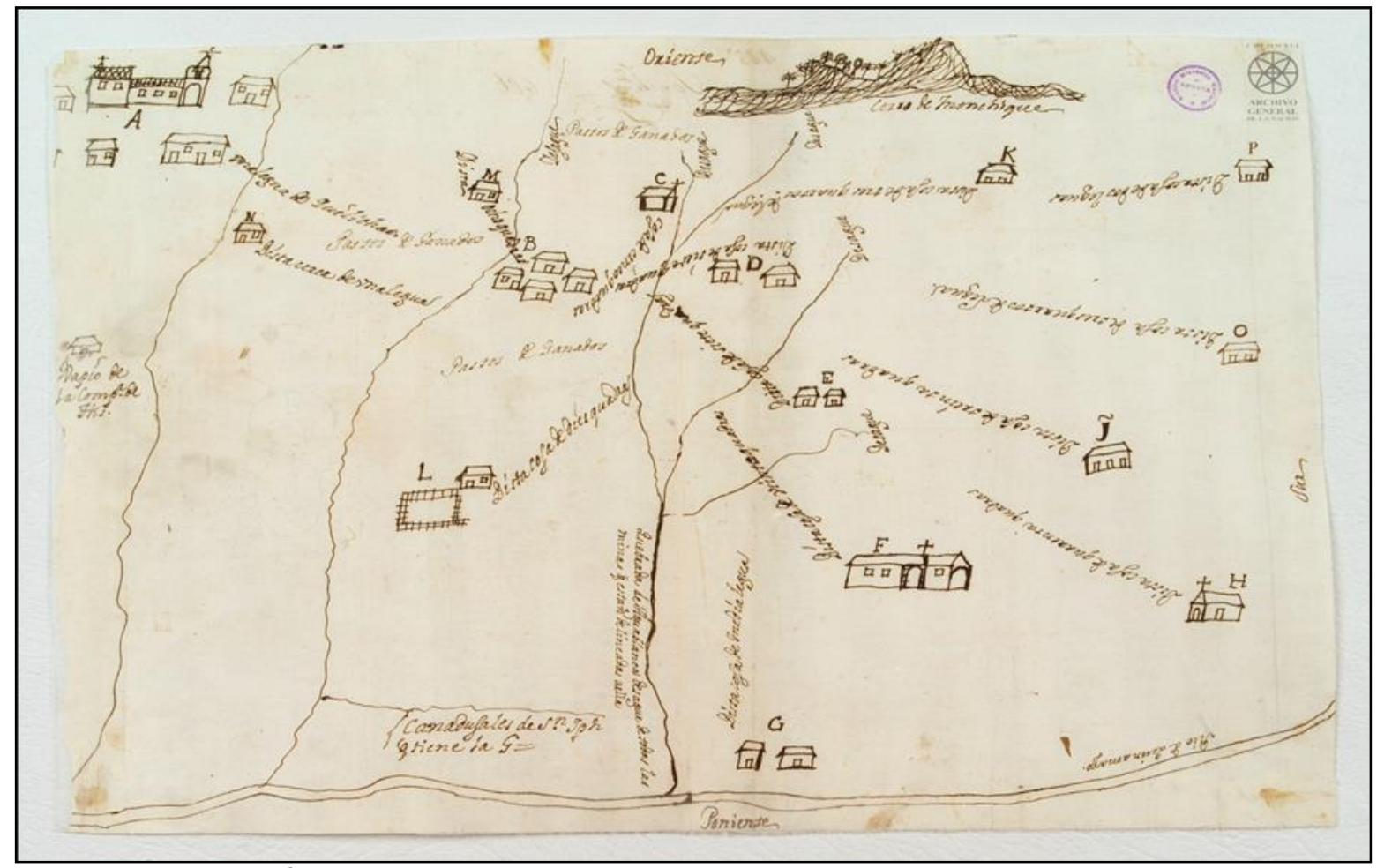

Fuente: AGN, Mapas y Planos, Mapoteca No. 4, 372-A.

La posibilidad de explotación de montes adyacentes, especialmente los montes denominados mochique o monchique identificados en el anterior mapa cerca del oriente, fueron otro de los elementos. Estos montes daban la posibilidad de obtener numerosos materiales indispensables para la subsistencia como paja para la construcción de techos de las casas, bejucos para la construcción de balsas, madera para arder fogones de cocina, construcción de casas, balsas y herramientas; y también brindaban alimentos frutales, semillas, animales de caza y plantas que sirvieron de alimentos y medicinas.

${ }^{20}$ Este mapa ubica la jurisdicción de Caloto desde los cerros de monchique en el oriente hasta la ribera derecha del Río Quinimayó en el poniente. Dentro de esta extensión se ubican los montes de monchique, la población de Caloto (A), el sitio de libres de Quilichao y su iglesia (B, C, D), las haciendas y potreros que cuentan con casa e iglesia (E, F, G, H, K, L, M, N, O, P) y los numerosos canales y quebradas que desembocan en el Río Quinimayó. 
Un último elemento que posibilitó el surgimiento del sitio de libres era la existencia de pastos naturales que junto a la presencia de montes, proveían condiciones idóneas para crianza de ganadería menor y mayor. Esas condiciones posibilitaron la formación de haciendas ganaderas para proveer carne a los centros poblacionales y a los esclavos que laboraban en las minas cercanas. Además los libres de Quilichao, aprovecharon estas condiciones para trabajar en dichas haciendas y para criar ganados menores como cerdos y cabras, y mayores como reses.

Cuadro No. 1: Número de habitantes de San Antonio de Quilichao por calidades

\begin{tabular}{|l|c|c|c|}
\hline \multicolumn{1}{|c|}{ Calidad } & Mujeres & Hombres & Total \\
\hline Blancos & 138 & 150 & 288 \\
\hline Mestizos & 61 & 64 & 125 \\
\hline Mulatos & 90 & 69 & 159 \\
\hline Negros & 63 & 53 & 116 \\
\hline Nobles & 7 & 7 & 14 \\
\hline Pardos & 62 & 48 & 110 \\
\hline Yndios & 12 & 7 & 19 \\
\hline Total & 433 & 398 & 831 \\
\hline
\end{tabular}

Fuente: Tabla elaborada a partir del Padrón de San Antonio de Quilicaho de 1791. AGN, PC, rollo 5, ff. 70or-706v.

Poblacionalmente, el surgimiento del sitio de libres se debe a varias razones. Entre las primeras está la paulatina llegada de población libre de otros sitios con ánimo de trabajar en las haciendas ganaderas, de acceder a la tierra y de comerciar bienes. A esto se agrega el proceso de mestizaje que se dio en la zona con indios y principalmente negros esclavos que laboraban en las minas adyacentes. Condiciones que se fortalecieron por el crecimiento vegetativo de los descendientes de esclavos y de blancos. Otra razón fueron los intentos de formar iglesia y poblado fueron uno de los incentivos que permitieron el establecimiento fijo en Quilichao de pobladores de diversa calidad, como se ve en el cuadro No. 1.

\section{Acceso a la tierra de los libres de Quilichao (1740-1762)}

Una cuestión central para establecer el acceso de los libres de Quilichao a la vecindad y al ejercicio del vasallaje, pasa por explicar cómo fue su acceso a la tierra. Éste estuvo mediado por un pleito por los derechos de propiedad sobre el enorme globo de tierra entre Caloto, los montes de monchique y el río Quinimayó (para mayor exactitud mirar 
el mapa número 1). Debemos decir que esta zona poseía recursos naturales abundantes comprendidos en pastos naturales, quebradas, ríos y montes vírgenes que lo hacían apto para desarrollar actividades forestales, extractivas, agrícolas y principalmente ganaderas. Además, contenía varios yacimientos auríferos que la hacían ideal para el comercio por la explotación del oro. Sobre este globo de tierra, existen dos posiciones diferentes en cuanto a su uso.

En primera instancia, debemos identificar los intereses sobre el acceso de tierras y los montes por parte de los libres de Quilichao. Eran tanto de subsistencia como comerciales; así, explotaban los montes con el objetivo de obtener maderas para la construcción de casas, balsas, herramientas y ciertos enseres; también, conseguían frutos, plantas y animales de caza para la alimentación; igualmente, habían logrado criar animales menores y ganados para la obtención de carne, cebo para velas y pieles; además, la feracidad de la tierra en algunos puntos lacustres les servían para la agricultura al obtener mieles, azúcar y aguardiente; por último, los cuerpos de agua les servían tanto para la movilidad de mercancías y personas, como para la extracción de piedras destinadas a la construcción de calles y edificios.

Por el contrario la familia Arboleda de Popayán, poseía intereses comerciales en el gran globo de tierra ya que éste comprendía un completo circuito económico. Inicialmente constaba de reales de minas que eran explotados, en varios puntos, siendo el de Quinimayó el más rentable; a su vez, comprendía también una numerosa fuerza de trabajo representada en esclavos quienes demandaban abastos constantemente; esta última situación llevó a la familia Arboleda a establecer una serie de haciendas y hatos ganaderos para comercializar carne, cebo y pieles, así como la crianza de yeguas y bestias de carga; lo que se completaba finalmente con la obtención de maderas de los montes cercanos.

Aunque durante un tiempo ambas posturas se lograron mantener sin conflictos, el problema apareció alrededor de 1750 cuando la familia Arboleda, representada primero por Francisco Antonio Arboleda y posteriormente por su hijo Julián Arboleda, decidieron hacer frente al uso, la ocupación y el avance de la población de libres de Quilichao sobre estas tierras. Fueron entonces, tres las acciones que emprendieron tanto padre como hijo para frenar y destruir -si era posible- la presencia de Quilichao.

La primera acción se orientó a reclamar en propiedad los terrenos de Quilichao, los montes de monchique y las minas de Quinimayó. Se pronunciaba entonces la familia 
argumentando que “...soy dueño de más de la mitad de las tierras llamadas Quilichao que colindan estas con el pueblo de el mismo nombre por Norte, y oriente en término que muchas de sus casas, están situadas entre los límites de mi terreno...” ${ }^{21}$. Tras reclamar su propiedad, la segunda acción de la familia Arboleda se encaminó a establecer un cobro de terraje a los libres de Quilichao; primero en dinero donde ofrecían en venta Real el resto o aquella parte, que necesitarán, y quiera comprarme, por su justo precio, el común de vecinos ${ }^{22}$ y también planteó un cobro en especie, especificando que "si por falta de dinero no pueden comprarlas les concederé el uso de ellas, pagándome por cada cien cargas de paja, que cortasen doce por el ciento de guaduas dos patacones = por el de caña cuatro reales, medio real por la carga de leña, y dos por las cien cargas de piedra de cantería” 23.

Otra alternativa que la familia Arboleda propuso fue el pago en forma de arriendo, donde "por cada solar de a veinte y cinco varas de frente, y el fono respectivo, y ocupasen con casas, o huertas, me darán anualmente ocho reales, y por las vacas y yeguas u otros animales, que pastasen en ellas un real por cabeza"24. Estas propuestas económicas y pactos de negociación, no les impedía pensar en ceder tierras a aquellos que no pudieran pagar ni de una, ni de otra manera, pensando en no "[...] incluir en estas contribuciones a los notoriamente pobres y menesterosos, que podrán disfrutar de ellas, sin interés alguno, dándome si, aviso para mi inteligencia y aún para el común de vecinos, protesto concederlas" 25 .

Para dar fuerza a sus peticiones, en su documentación los Arboleda también agregaban quejas aduciendo daños y perjuicios que los libres infringían a sus posesiones

[...] que con las continuadas sacas de madera, y guaduas que han executado las minas de las carmelitas y campos, como así mismo los asistentes de Quilichao han abierto varios pasos del potrero de San Antonio, y Potrerillo de donde se han originado varios quebrantos, al dueño con salirse a la sabana los novillos de ceba, y los ganados mayores de cría, con la oportunidad de topar los potreros abiertos, y sin cerca se entran en dichos potreros, y se misturan unos, con otros, y se sigue de este

\footnotetext{
${ }^{21}$ AGN, PC, Rollo 5, f. 582r.

${ }^{22}$ AGN, PC, Rollo 5, f. 582 r.

23 AGN, PC, Rollo 5, f. 582 r.

24 AGN, PC, Rollo 5, f. 582r.

${ }_{25}$ AGN, PC, Rollo 5, f. 582r.
} 
desorden de enflaquecerse unos y otros ganados, y redunda entonces no poder el que lo presenta dar providencia de carne a su numerosa cuadrilla [...].26

Como también aducen alteraciones al orden público “[...] que sabe por haberlo visto de los desórdenes que resultan en las cuadrillas de esclavos y vicios en el aguardiente y robos y otras operaciones de igual naturaleza, son ocasionados únicamente del trato y contrato de aquellos libres con los esclavos, y así sucede siempre, en los parajes que seles admite este trato [...]" ${ }^{27}$, se lamentaba la familia Arboleda en una de sus quejas. En resumen, las acciones que emprenden los Arboleda están motivadas por la posesión de la tierra y la alteración a su circuito comercial que suponían los libres de Quilichao.

Como respuesta la población de libres se movilizó en pro de defenderse y para ello se pronunció a través de un apoderado. Los descargos que hicieron los libres fueron varios, los cuales podemos agrupar de la siguiente manera: el primer grupo se orientó a advertir que los terrenos habían sido realengos y cuya posesión ya se les había concedido, “[...] en el amparo que dio Don Josef y Pando quando vino de visitador de tierras, consta la y títulos que dio a los vecinos de este Asiento de San Antonio de Quilichao" ${ }^{28}$.

Amparo donde además “[...] reza de sus linderos desde el pie de la loma, al oriente y lado o faldas del cerro, y montañas de Monchevique, tomando la longitud de poniente a la madre Vieja del Rio Quinamayo, que se comprende con parte de los montes bajos de potrerillo, y en latitud desde la quebrada que llaman de Aguasucia o Aguablanca hasta el zanjon de Xapio que es camino Real en rectitud, que linda con las haciendas que fueron de los padres expatriados" ${ }^{29}$. Este tipo de descargos fueron realizados por los libres para desvirtuar la supuesta propiedad de los Arboleda sobre las tierras en disputa.

A lo que sumaron un inconveniente que resultaba a petición de Arboleda al pedir en propiedad el globo de tierra que comprendía a población de Quilichao, los montes de mochique y las minas, los libres explicaban "[...] que asi estas, como aquellas quedan en el centro del inmenso globo de tierras que posee solamente en esta el referido Don Fran-

${ }^{26}$ AGN, PC, Rollo 5, f. 632r.

${ }_{27}$ AGN, PC, Rollo 5, f. 671r.

28 AGN, PC, Rollo 4, f. 732r.

29 AGN, PC, Rollo 4, f. 732r. 
cisco Antonio y con este motivo se llama hoy a la propiedad de todas las tierras impidiendo el que se funden las familias crecidas que hay hoy en el día en este lugar [...]"30 Ellos enfatizaban que eran una población nómada, y que por el contrario ya se habían establecido formalmente en el sitio con sus familias desde algún tiempo.

Por otra parte, los libres denotaron su condición económica como gente pobre, diciendo que "...ya con privarnos el huzo de un pedacito de tierra que cada individuo puede ocupar para fundar un hospicio en donde alojarse con su familia, ya de maderas, pajas, y todo material que es preciso y necesario para la fijeza [Sic] y aumento de un lugar, y de campos para labrar y cultivar y por este medio sostener y mantener familias mui crecidas y mui pobres [...]"31. Tal argumentación se dirigió a justificar desde su condición, la ocupación de los terrenos y la negativa de pagar ante la intención de los Arboleda de cobrarles terraje.

Por último, en un tercer grupo, los libres señalaron los múltiples atropellos que sufrían por parte de la familia Arboleda que iban desde la confiscación de sus productos:

[...] decir aun que no se acuerda que sujetos les quitaron pajas cañales y guaduas pero que cuio toda la paja cortada y despedasada toda la caña y la guadua la vio llevar a la acienda del ato; y que en el tiempo de Don Francisco Josef Arboleda le quitaron la leña a Carlos Tovar según se lo dijo este y a otras personas lo ha oydo; que a Julian le quitaron quatro cargas de guadua digo paja y se las llevaron a la hacienda del alto $[\ldots] .3^{32}$

\footnotetext{
30 AGN, PC, Rollo 4, f. 732r

${ }^{31}$ AGN, PC, Rollo 4, f. 726v.

${ }^{2}$ AGN, PC, Rollo 4, f. 732r.
} 
Mapa No. 2: Tierras de Quilichao entre el Río de la Paila y el Río Palo (1786)

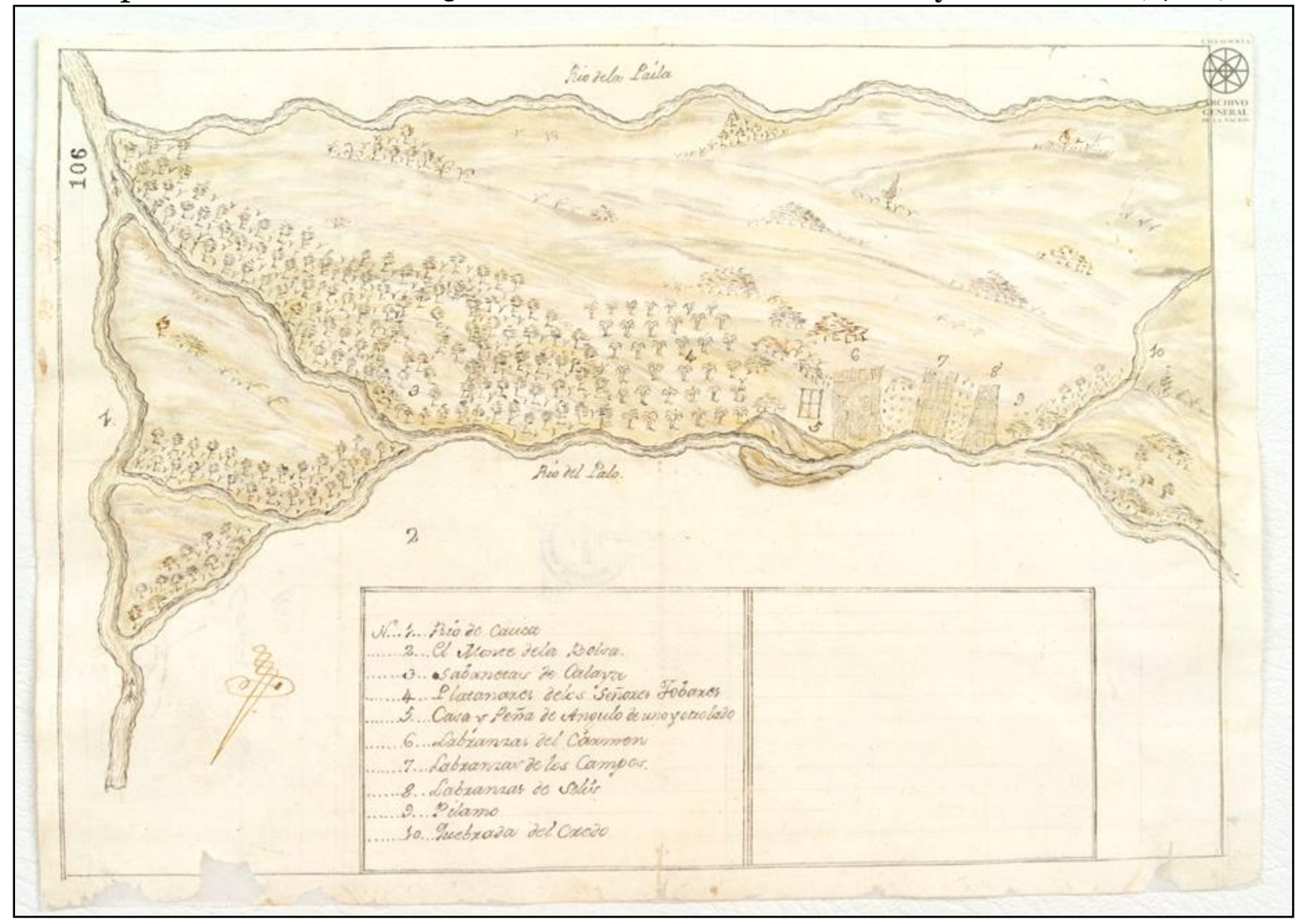

Fuente: AGN, Mapas y Planos, Mapoteca No. 4, 639-A.

Visto este cruce de acusaciones de la familia Arboleda y de quejas por parte de los libres de Quilichao, las autoridades evaluaron una serie de elementos a favor que tenían los libres. Uno de ellos, era el hecho de vivir en comunidad donde "[...] cierto que Quilichao es población bastante crecida de regular vecindario y cacerías de paja con plaza y algunas calles arregladas con proporción de poderlo arreglar más [...]"33; benéfico era también el hecho que usaban y explotaban las tierras a través de la ganadería y del cultivo de varios frutos de la tierra en distintas labranzas y platanares como se aprecia en el mapa No. 2.

33 AGN, PC, Rollo 4, f. 75or. 
Una última ventaja que poseían los libres frente la petición de los Arboleda era el hecho de que su comercio servía de abasto a las haciendas, minas y ciudades, señalando las autoridades que “...es cierto que hay regular comercio de ropas, más de la tierra que de castilla por ser aquellos lo que más se gasta: que hay mercaderes y forasteros y patricios y algunas pulperías y que es cierto que los hacendados de la jurisdicción pueden vender algunos frutos de sus haciendas siendo entre estos el plátano y maíz pudiendo al mismo tiempo proveérsele las ropas y menesteres para sus familias de aquellas que aquí se pasta en el común de estas gentes...”34.

Teniendo en cuenta los argumentos de los Arboledas y de los libres, las autoridades en este caso la Real Audiencia de Santafé en apoyo de la Gobernación de Popayán- tomaron una decisión final sobre el asunto. Dichas autoridades, partieron de los límites de 1762 establecidos por el visitador de tierras Don Joseph y Pando, el cual había señalado claramente y en cierta forma de manera equitativa, las tierras que pertenecían a Caloto - primer cuadro-, a Quilichao, a los padres expatriados y los Arboledas -segundo cuadro-, y a las minas de Quinimayó (tercer cuadro), división representada en el siguiente mapa.

34 AGN, PC, Rollo 4, f. 751r. 
Mapa No. 3: Tierras de Caloto, de Quilichao, de los arboledas y Quinimayó (1762)

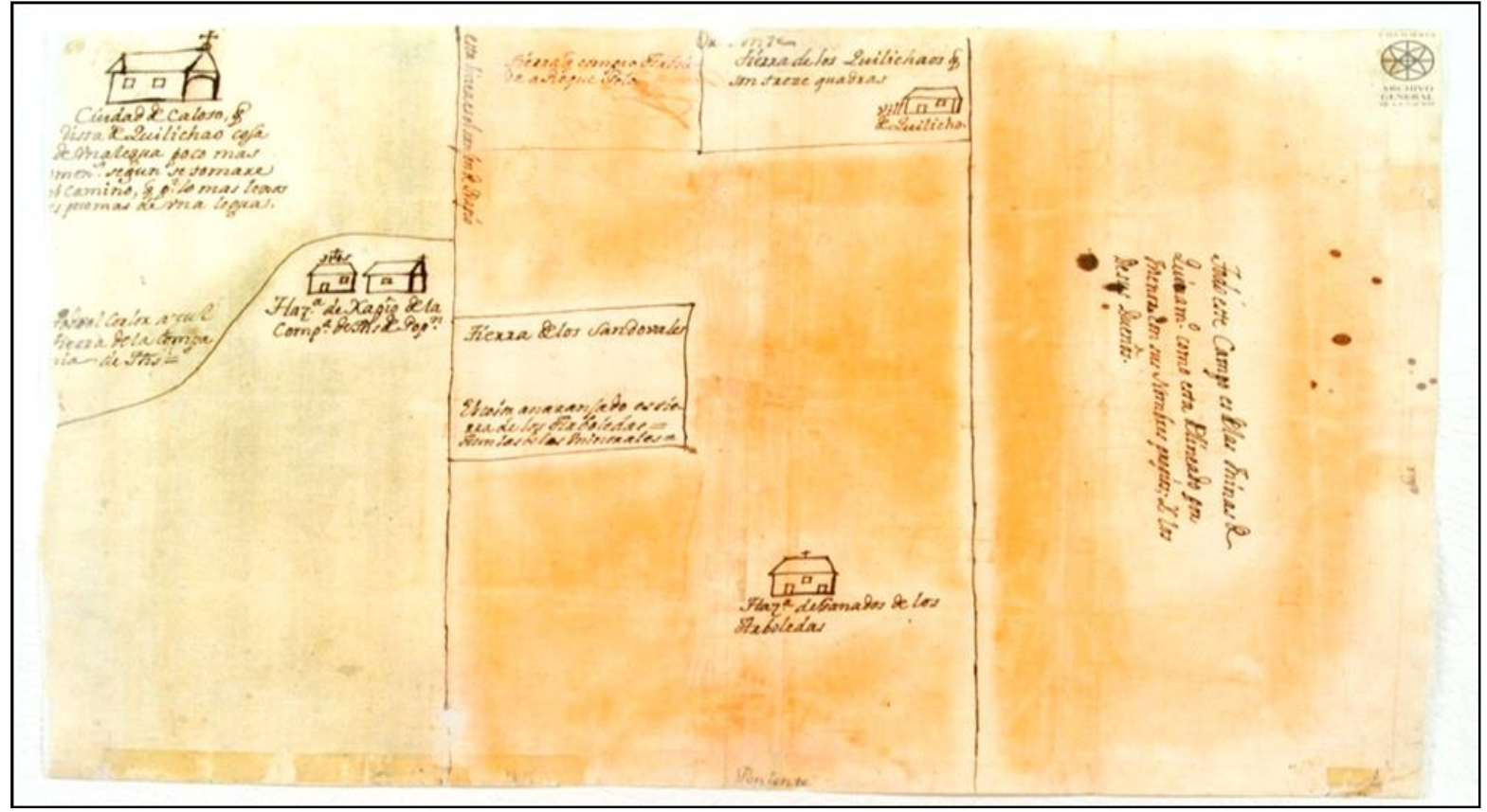

Fuente: AGN, Mapas y Planos, Mapoteca No. 4, 371-A.

Partiendo de esa base, a los libres se les concedió el uso y acceso a la tierra y a la explotación de los montes que quedaban comprendidos dentro de los límites otorgados por Joseph y Pando en 1762, donde se les proporciona además “[...] ejidos, a lo menos media legua de largo por cada lado de los quatro frentes de la, franqueando a los dueños de las tierras por permuta otra tanta en parte diversa, $o$ al vecindario el precio en que las compraron y que determinando el asunto con voto consultivo de esa mi Real Audiencia $[\ldots] " 35$.

Las autoridades también decretaron que la población de Caloto mantuviera casa abierta dictaminando que "[...] se obligue a los que tienen haciendas en la ciudad de Caloto, a mantener casa abierta en ella, havitandola por sus personas, o a lo menos con su familia

35 AGN, PC, Rollo 4, f. 765r. 
[...]"36, esto con el fin de proporcionar las herramientas para la explotación de la tierra $\mathrm{y}$ fomentar un comercio que favoreciera a ambas poblaciones.

Adicionalmente, tanto la familia Arboleda como los libres de Quilichao decidieron negociar sobre las partes de tierra que efectivamente pertenecían a la familia según límites de 1762. Ante la propuesta de los Arboleda de pagar terraje, los libres aceptaron parcialmente este punto, expresando el apoderado de Quilichao que

[...] se me hizo saber por el presente escribano; ante vuestra señoría conforme a derecho y con el más debido respeto y digo teniendo muy presente, estos vecinos de tierras, y montes para la conservación y fomento de la población, y que cualquiera gracias se de en beneficio del vecindario, son desde luego admisibles las ofertas del expresado Doctor Don Julián de Arboleda, que a la verdad son muy propias, de su generosidad y magnánimo corazón ${ }^{37}$.

Junto a esta aceptación, los libres acompañaron una petición hacia las autoridades expresándoles que "[...] en el se le concede la gracia, que se impetrase por la del Doctor Don Julián de Arboleda, corra provisionalmente el uso de tierras y montes, que se necesiten en los términos de la concesión, dignándose autorizarla a Vuestra Señoría por su judicial decreto [...]" 38 . No sabemos si la petición fue aceptada o no, lo que si podemos asegurar fue que Quilichao continuó creciendo y avanzando sobre estas tierras. En conclusión, fue gracias a las soluciones alcanzadas por las autoridades y por la negociación entre las partes, que los libres de Quilichao logran acceder al uso y derechos sobre gran parte de la tierra que ocupaban mediante la cesión de tierras comunales y el pago de terraje a los Arboledas.

\section{Acceso al mercado: artículos básicos y de consumo}

La Gobernación de Popayán consideraba que Quilichao era una arteria central en el abastecimiento de Cali, Popayán, la jurisdicción de Buga, y otras altitudes con algunos pueblos cercanos como por ejemplo Guambia y la parroquia del Carmen. Pudimos así detectar pequeñas economías estables; bien es el caso del partido de Quilichao donde necesariamente se conectaban a otros mercados rurales y en menor escala con centros

${ }^{36}$ AGN, PC, Rollo 4, f. 766r.

37 AGN, PC, Rollo 5, f. 584 r.

${ }^{8} 8$ AGN, PC, Rollo 5, f. 584v. 
urbanos, principalmente por productos básicos de primera necesidad como sal, azúcar, miel y carne de la crianza de ganado.

Posteriormente a nivel local, la gobernación entregó libertad de alcabalas en todas las mercancías producidas en el asiento con el objetivo de nutrir a las principales ciudades cercanas, ampliando así la "jurisdicción comercial" y dando carta abierta para que también llegaran mercancías de otros pueblos y se comercializaran desde Quilichao. Veamos entonces la relación de la siguiente tabla donde podemos apreciar el florido comercio del poblado ya entrado el siglo XIX, y el deseo que manifestaban sus habitantes por pagar impuestos voluntariamente y declarar el tipo de actividad comercial a la que se dedicaban:

Es menester considerar que ya estábamos hablando de grupos poblacionales bien conformados, capaces de conectarse a pequeños mercados que a partir de productos básicos daban inicio a fuertes vínculos económicos para nada cercanos de la autarquía y cada vez conectándose y creciendo39. Nos permitimos entonces resaltar el esfuerzo de los $l i$ bres por usar las instituciones locales; sabemos que la administración de alcabalas concedía para el año de 1803 la guía para conducir productos básicos, que permitía a los de Quilichao, puntual y voluntariamente, pagar los impuestos necesarios y normales dentro de la movilidad comercial, que en otros términos sería la ampliación de la jurisdicción comercial como se consentía en la función del Rey.

39 Ver Maurice Aymard. “Autoconsumo y mercados: ¿Chayanov, Labrousse o Le Roy Ladurie?”, en mercados e Historia, edit. Juan Carlos Grosso y Pablo Silva Riquer. México: Instituto Mora, 1964, 69-78. 
Tabla No. 2

Relación de alcabalas, mercancías y licencias en el partido de Quilichao para el año de $1803^{40}$.

\begin{tabular}{|c|c|c|c|c|c|c|c|}
\hline $\begin{array}{l}\text { Nombres y } \\
\text { Apellidos }\end{array}$ & Concepto & Valor & Patria & Destino & $\begin{array}{l}\text { Fecha de } \\
\text { licencia }\end{array}$ & $\begin{array}{l}\text { Fecha de } \\
\text { llegada }\end{array}$ & Folios \\
\hline $\begin{array}{l}\text { Eugenio He- } \\
\text { rrera }\end{array}$ & $\begin{array}{l}\text { Pagó por haber } \\
\text { vendido sus car- } \\
\text { gas de azúcar en } \\
\text { Quilichao. }\end{array}$ & $\begin{array}{l}\text { Ajusta el } \\
\text { valor de } \\
\text { seis reales }\end{array}$ & Caloto & Quilichao & & $\begin{array}{c}\text { Febrero } \\
11\end{array}$ & $\begin{array}{l}\text { Fol. } \\
\text { 92.r. }\end{array}$ \\
\hline $\begin{array}{l}\text { Eugenio He- } \\
\text { rrera }\end{array}$ & $\begin{array}{l}\text { Por la alcabala de } \\
\text { cinco, y más car- } \\
\text { gas de azúcar. Y } \\
\text { se mojó y perdió } \\
\text { completamente } \\
\text { un tercio. }\end{array}$ & $\begin{array}{l}\text { Pagó la } \\
\text { suma de } \\
\text { dos pesos } \\
\text { más real. }\end{array}$ & Caloto & Quilichao & & $\begin{array}{l}11 \mathrm{Fe}- \\
\text { brero }\end{array}$ & 92.v. \\
\hline $\begin{array}{l}\text { Juan Josef de } \\
\text { Ocampo }\end{array}$ & $\begin{array}{l}\text { Guía para trasla- } \\
\text { dar una carga de } \\
\text { arroz y otra de } \\
\text { azúcar a Doña } \\
\text { Catarina Iz- } \\
\text { quierdo en su dis- } \\
\text { pendio. }\end{array}$ & $\begin{array}{l}\text { Cinco y } \\
\text { más reales. }\end{array}$ & Buga & Quilichao & $\begin{array}{l}\mathrm{O} 2 \text { de } \mathrm{Fe}- \\
\text { brero }\end{array}$ & $\begin{array}{l}12 \text { de Fe- } \\
\text { brero. } \\
\text { Pagó Don } \\
\text { Josef } \\
\text { María } \\
\text { Sar- } \\
\text { miento } \\
\text { por su es- } \\
\text { posa. }\end{array}$ & 93.v. \\
\hline $\begin{array}{l}\text { Francisco } \\
\text { Mota }\end{array}$ & $\begin{array}{l}\text { Diez y siete car- } \\
\text { gas de sal. }\end{array}$ & Seis reales & Quilichao & Quilichao & Abril 18 & Abril 18 & 94.v. \\
\hline $\begin{array}{l}\text { Toribio Anto- } \\
\text { nio Posada }\end{array}$ & $\begin{array}{l}\text { Veinte y cuatro } \\
\text { arrobas de cacao, } \\
\text { contenidas a las } \\
\text { ventas reguladas } \\
\text { a diez arrobas por } \\
\text { carga. }\end{array}$ & $\begin{array}{l}\text { Dos pesos y } \\
\text { seis reales. }\end{array}$ & Quilichao & $\begin{array}{l}\text { A los luga- } \\
\text { res de } \\
\text { Buga, Cali } \\
\text { y Popayán } \\
\text { para su ex- } \\
\text { pendio. }\end{array}$ & Abril 14 & Abril 14 & 95.r. \\
\hline $\begin{array}{l}\text { Juan Fran- } \\
\text { cisco Castro }\end{array}$ & $\begin{array}{l}\text { A nombre de Don } \\
\text { Feliciano Men- } \\
\text { dez, alcabala de } \\
\text { trece cargas de } \\
\text { sal, vendió siete } \\
\text { cargas. }\end{array}$ & $\begin{array}{l}\text { Cuatro pe- } \\
\text { sos, siete } \\
\text { reales. }\end{array}$ & Quilichao & Caldono & $\begin{array}{l}24 \text { de } \\
\text { Marzo }\end{array}$ & Abril 14 & 96.v. \\
\hline $\begin{array}{l}\text { Gabriel Per- } \\
\text { domo y capo- } \\
\text { ral Juan Josef } \\
\text { Trujillo }\end{array}$ & $\begin{array}{l}\text { Conduce quince } \\
\text { cargas de sal a } \\
\text { despenderlas. Pa- } \\
\text { gará el derecho } \\
\text { de alcabala y no }\end{array}$ & $\begin{array}{l}\text { Cinco Pe- } \\
\text { sos, cinco } \\
\text { reales }\end{array}$ & $\begin{array}{l}\text { Parroquia } \\
\text { el Carmen }\end{array}$ & $\begin{array}{l}\text { Popayán, } \\
\text { Quilichao, } \\
\text { lugares de } \\
\text { la provin- } \\
\text { cia o de ese }\end{array}$ & Abril 25 & $\begin{array}{l}13 \text { Abril } \\
\text { Pagó } \\
\text { Juan Jo- } \\
\text { sef Truji- } \\
\text { llo }\end{array}$ & \\
\hline
\end{tabular}

$4^{\circ 0}$ A.G.N. Archivo Anexo II, administración de Alcabalas, Mercancías, Licencias, Cauca, (1797-1831) caja 002, Carpeta 002. Fol. 1-210. 


\begin{tabular}{|c|c|c|c|c|c|c|c|}
\hline & $\begin{array}{l}\text { le pondrá emba- } \\
\text { razo para su } \\
\text { venta: los minis- } \\
\text { tros del res- } \\
\text { guardo. }\end{array}$ & & & $\begin{array}{l}\text { mismo } \\
\text { producto }\end{array}$ & & & \\
\hline $\begin{array}{l}\text { Don Pedro y G } \\
\text { Coronado }\end{array}$ & $\begin{array}{l}\text { Con su caporal } \\
\text { 70, más Perdomo } \\
\text { (Representante). } \\
\text { Veintiuna cargas } \\
\text { de sal. }\end{array}$ & $\begin{array}{l}\text { Siete Pesos } \\
\text { y Siete } \\
\text { reales. }\end{array}$ & $\begin{array}{l}\text { Parroquia } \\
\text { del Carmen }\end{array}$ & $\begin{array}{c}\text { A despen- } \\
\text { der las en } \\
\text { las ciuda- } \\
\text { des de Po- } \\
\text { payán, } \\
\text { Quilichao, } \\
\text { o lugares } \\
\text { de la pro- } \\
\text { vincia. }\end{array}$ & & $\begin{array}{c}\text { Mayo 14 } \\
\text { Pagó To- } \\
\text { mas Per- } \\
\text { domo. }\end{array}$ & $\begin{array}{l}\text { 98.r, } \\
\text { 98.v. }\end{array}$ \\
\hline $\begin{array}{l}\text { Manuel José } \\
\text { Perdomo } \\
\text { Con su caporal } \\
\text { Juan Gil Vidal }\end{array}$ & $\begin{array}{l}\text { Guía para condu- } \\
\text { cir Veinte cargas } \\
\text { de sal con sus } \\
\text { mulas. }\end{array}$ & $\begin{array}{l}\text { Dieciocho } \\
\text { reales } \\
\text { (como en- } \\
\text { cargado del } \\
\text { morcillo) } \\
\text { [sic] }\end{array}$ & $\begin{array}{l}\text { Parroquia } \\
\text { del Carmen }\end{array}$ & & $\begin{array}{l}13 \text { de } \\
\text { Mayo }\end{array}$ & $\begin{array}{l}\text { Abril } 29 \\
\text { de } 1803\end{array}$ & 99.r. \\
\hline $\begin{array}{l}\text { Tomas de Na- } \\
\text { via }\end{array}$ & $\begin{array}{l}\text { Guía para condu- } \\
\text { cir una carga de } \\
\text { Cacao, para la } \\
\text { venta. }\end{array}$ & & Popayán & Quilichao & & $\begin{array}{l}\text { Plazo de } \\
\text { 3o días, } \\
\text { queda } \\
\text { obligado } \\
\text { por el ad- } \\
\text { ministra- } \\
\text { dor de al- } \\
\text { cabalas. }\end{array}$ & $\begin{array}{l}\text { 10o.r.1 } \\
\text { oo.v. }\end{array}$ \\
\hline $\begin{array}{l}\text { Josef Joaquín } \\
\text { Caicedo }\end{array}$ & $\begin{array}{l}\text { Pago de carga de } \\
\text { cacao }\end{array}$ & $\begin{array}{l}\text { Nueve } \\
\text { reales }\end{array}$ & Quilichao & & Junio 5 & $\begin{array}{c}19 \mathrm{de} \\
\text { Abril de }\end{array}$ & 100.v. \\
\hline $\begin{array}{l}\text { Don Pedro y G } \\
\text { Coronado y su } \\
\text { caporal Josef } \\
\text { Andrada }\end{array}$ & $\begin{array}{l}\text { Quince cargas de } \\
\text { sal. }\end{array}$ & & $\begin{array}{l}\text { Parroquia } \\
\text { del Carmen }\end{array}$ & $\begin{array}{l}\text { A despen- } \\
\text { derlas en } \\
\text { Popayán, } \\
\text { Quilichao o } \\
\text { la Provin- } \\
\text { cia. }\end{array}$ & Julio 27 & Junio 20 & $\begin{array}{l}\text { 101. r. } \\
101 . v .\end{array}$ \\
\hline $\begin{array}{l}\text { Jose Joaquín } \\
\text { Rengifo }\end{array}$ & $\begin{array}{l}\text { Cinco cargas de } \\
\text { harina con afre- } \\
\text { chos, caña y ajos }\end{array}$ & $\begin{array}{l}\text { Pagó Siete } \\
\text { y medio } \\
\text { reales por } \\
\text { la alcabala } \\
\text { de cinco } \\
\text { cargas de } \\
\text { harina. Y } \\
\text { medio real } \\
\text { de tres pe- } \\
\text { sos, en que } \\
\text { vendió una } \\
\text { arroba de } \\
\text { ajos. }\end{array}$ & Guambia & Quilichao & $\begin{array}{l}22 \mathrm{de} \\
\text { septiem- } \\
\text { bre }\end{array}$ & $\begin{array}{l}\text { Agosto } \\
\text { O1 }\end{array}$ & $\begin{array}{l}\text { 102. r. } \\
\text { 102.v. }\end{array}$ \\
\hline $\begin{array}{l}\text { Josef María } \\
\text { Muñoz }\end{array}$ & $\begin{array}{l}\text { Guía para condu- } \\
\text { cir cargas de miel } \\
\text { para la venta }\end{array}$ & & Quilichao & Guambia & $\begin{array}{l}\text { O3 de no- } \\
\text { viembre }\end{array}$ & $\begin{array}{l}\text { Plazo de } \\
\text { veinte } \\
\text { días. }\end{array}$ & 106.r. \\
\hline
\end{tabular}




\begin{tabular}{|l|l|l|l|l|l|} 
Rengifo & $\begin{array}{l}\text { Seis Cargas de } \\
\text { miel para la } \\
\text { venta. }\end{array}$ & Quilichao & Guambia & $\begin{array}{l}\text { Plazo de } \\
\text { veinte } \\
\text { días. }\end{array}$ & 109.r. \\
\hline
\end{tabular}

Fuente: tabla elaborada a partir de datos contenidos en la "Administración de Alcabalas, Mercancías, Licencias, Cauca (1797-1831” en AGN, Archivo Anexo II, caj. 002, carp. 002, fols. 1-210.

Un ejemplo de esa ampliación sucedió con Guambia, que era una población compuesta mayoritariamente por indígenas ${ }^{41}$; conocimos que existía un vínculo comercial entre Guambia y Quilichao, y en ambas partes observamos que se apeló a la administración de alcabalas para hacer uso del "derecho al comercio", y con frecuencia no sólo para trasladar productos, sino para pagar debidamente una parte de las utilidades. Estas pequeñas economías campesinas así fueron el mosaico perfecto para establecer vínculos sociales sólidos en los que conocimos las uniones matrimoniales de libres residentes en Quilichao con individuos de otras patrias, integrados como vecinos en ciudad, o en condición de libres.

\section{Conclusiones}

Debemos considerar entonces, que la población libre pudo acceder a la tenencia de la tierra y darle variados usos que permitieron extraer los recursos necesarios para la propagación y progreso del poblado. Consumado lo anterior, no es baladí tener en cuenta que accedieron a la vecindad, lo cual les otorgaría derechos y deberes en comunidad que crecieron como una obligación individual. La diversidad de actividades que desarrollaron los libres de Quilichao y la suma de estas condiciones fomentó la formación de pequeñas economías internas en el sitio, las cuales manejaban cierta producción agrícola -sal, azúcar, miel, aguardiente-, una fuerte cría de ganados -carne salada-, la presencia de pulperías -comercio de ropas, velas, alimentos, bienes artesanales- y el manejo de una red de distribución comercial a través de los caminos reales, caminos clandestinos y canales de navegación fluvial. Economías internas que además se conectaban a varios mercados cercanos en Popayán y distantes como Cartago. Este elemento de desarrollo y de acceso al mercado, resultó clave para concretar su asentamiento, oficios y vecindad. Por último es menester resaltar, acerca de la diversidad de oficios y servicios que ofrecían, que bien eran distintos a los artículos que producían hablamos entonces de sociedades conformadas alentadas en su crecimiento y adelanto por el abrigo de las

${ }^{41}$ A.G.N., Poblaciones del Cauca, caciques-indios, Rollo 22, D.9/ indios de Jámbalo: Quejas por el usufructo de resguardos f.684.r. 
reformas borbónicas, que bien repercutían en que alcanzaran el dinamismo de sociedades en pleno ascenso.

\section{Bibliografía}

\section{Fuentes primarias}

Archivo General de la Nación (AGN), Bogotá, Colombia. Poblaciones del Cauca, Rollo 4, 5 y 6; Mapoteca 4; Administración de Alcabalas, Mercancías, Licencias (Cauca) Archivo Anexo II, Caja 2, Carpeta 2.

\section{Fuentes secundarias}

Bolaños Rodas, Richard A. "El Impacto del Reformismo Borbónico en la Nueva Granada. El caso de los indios de Jámbalo y el asiento de libres de San Antonio de Quilichao en la Jurisdicción de Caloto, Provincia de Popayán 1750- 1810”. Tesis de pregrado, Cali: Universidad del Valle, 2013.

Brading, David. "La España de los Borbones y su imperio americano”. En América Latina en la época colonial, compilado por Miguel León Portilla, Madrid: Crítica, 1990, 85-126.

Colmenares, Germán. La Independencia, Ensayos de Historia Social: Castas y Patrones de Poblamiento y conflictos sociales en las provincias del Cauca 1810-1830. Bogotá: Colección autores nacionales, 1986, 137-182.

Garrido, Margarita. Libres de todos los colores en la sociedad colonial tardía: discursos y prácticas, Cali: Universidad del Valle, 1998.

Garrido, Margarita. Reclamos y representaciones. Variaciones sobre la política en el nuevo Reino de Granada, 1770-1815. Bogotá: Banco de la República, 1993.

Herrera, Marta. "Libres de todos los colores": el ordenamiento social en las llanuras del Caribe, siglo XVIII". En El Caribe colombiano en la nación colombiana, Memorias X Cátedra Anual de Historia "Ernesto Restrepo Tirado", editado por Alberto Abello Bogotá: Museo Nacional de Colombia/Observatorio del Caribe Colombiano, 2006.

Herrera, Marta. Ordenar para controlar. Ordenamiento espacial y control político en las Llanuras del caribe y en los Andes Centrales Neogranadinos. Siglo XVIII. Bogotá: Instituto Colombiano de Antropología e Historia- Academia Colombiana de Historia, 2002.

Herrera, Marta. Popayán, la unidad de lo diverso: territorio, población y poblamiento en la Provincia de Popayán, siglo XVIII. Bogotá: Uniandes, 2009. 
Herzog, Tamar. "Nombres y apellidos: ¿cómo se llamaban las personas en Castilla e Hispanoamérica durante la época moderna?”. En Jahrbuch Für Geschichte Lateinamerikas, No. 44, Böhlau Verlag Köln, Weimar, Wien 2007.

Herzog, Tamar. Vecinos y Extranjeros. Hacerse español en la edad moderna. Madrid: Alianza, 2006.

Lempérière, Annick. Entre Dios y el Rey: la República, la cuidad de México de los siglos XVI-XIX. México: Fondo de Cultura Económica, 2013.

Mc Farlane, Anthony. "Renovación: el establecimiento del Virreinato”. En Colombia antes de la Independencia. Bogotá: Banco de la República, 1997.

Meisel Roca, Adolfo. "Esclavitud, mestizaje y haciendas en la provincia de Cartagena. 1533-1851". En El Caribe colombiano. Selección de textos históricos, editado por Gustavo Bell Lemus, Barranquilla: Universidad del Norte, 1988.

Mejía, Eduardo. Campesinos, poblamiento y conflictos: Valle del Cauca 180o-1848. Cali: Univalle, 2002.

Monod, Paul. "Estado, nación y monarquía en el siglo XVIII: visión comparativa". En Las monarquías del Antiguo Régimen, ¿̇monarquías compuestas?, Madrid: Editorial Complutense, 1996, 11-29.

Sánchez, Hugues. "Amancebamiento, poligamia, lujuria y otros excesos de la población libre en el Caribe Colombiano. El nacimiento de una Cultura. 1750-1880". En editores Hugues Sánchez y Leovedis Martínez. Historia, Identidades, Cultura Popular y Música Tradicional en el Caribe Colombiano. Valledupar: Ediciones Unicesar, 2004, 45-60.

Sánchez, Hugues. "De esclavos a campesinos, de la "roza" al mercado: tierra y producción de los "libres de todos los colores" en la gobernación de Santa Marta (17401810)”. En Historia Crítica, No. 43, Enero-Abril, Bogotá: Uniandes, 2011, 130-155.

Sánchez, Hugues. "Tenencia de la tierra, mano de obra, mercados y productividad en la frontera: españoles, indígenas y comunidades campesinas en la gobernación de Santa Marta, 1700-1810”. Tesis de Doctorado, Sevilla: Universidad Pablo de Olavide, 2010.

Valencia, Alonso. "La Insurgencia Social y la Consolidación de los Campesinos Vallecaucanos", en Historia y Espacio, $\mathrm{N}^{\circ}$ 21, Julio-Diciembre, Cali: Univalle, 2003, 5372.

Zuluaga, Francisco. La Protesta Social en el Suroccidente Colombiano Siglo XVIII. Cali, Univalle, 1997. 
